\title{
Reutilização de terra diatomácea residual proveniente da produção de soros antiofídicos e antitóxicos
}

\author{
Reuse of residual diatomaceous earth from \\ manufacturing of antiophidic and \\ antitoxic sera
}

\begin{abstract}
Ricardo Adriano Dorledo de Faria ${ }^{1}$, Tássia Gabriela Guimarães Pereira Silva ${ }^{2}$, Renata Braga Soares ${ }^{1}$, Christianne Garcia Rodrigues ${ }^{2}$
\end{abstract}

\footnotetext{
${ }^{1}$ Universidade Federal de Minas Gerais - UFMG. Departamento de Engenharia Química, Av. Presidente Antônio Carlos, 6627, CEP 31270-901, Belo Horizonte, Minas Gerais, Brasil.

${ }^{2}$ Centro Universitário de Belo Horizonte - UniBH. Instituto de Engenharia e Tecnologia, Av. Professor Mário Werneck, 1480, CEP 30455-610, Belo Horizonte, Minas Gerais, Brasil.

e-mail: ricardo.adriano08@hotmail.com, renatabragasoares@yahoo.com.br, tassiaguimaraesp@hotmail.com, christianne.garcia@unibh.br
}

\section{RESUMO}

Na produção de soros antiofídicos e antitóxicos, comumente se utiliza a terra diatomácea, que é um mineral leve, de baixa massa específica e com alto potencial de adsorção, sendo este comumente empregado em processos de filtração. A fim de se reutilizar a terra residual dos processos de filtração de soros antiodíficos e antitóxicos da Fundação Ezequiel Dias, este trabalho propôs sua recuperação via tratamento térmico. Após Análise Termogravimétrica da terra diatomácea residual, concluiu-se que a partir de $600^{\circ} \mathrm{C}$ todas as impurezas presentes neste material haviam sofrido degradação. Assim, uma amostra do mineral saturado foi aquecido em forno mufla até a temperatura de $700^{\circ} \mathrm{C}$. Em seguida, a influência do tratamento térmica nas propriedades do mineral foi avaliada por meio da determinação dos parâmetros físico-químicos como $\mathrm{pH}$, densidade aparente, teor de umidade base seca e seu potencial de adsorção em plasma equino hiperimune, principal característica para sua aplicação no processo de filtração para obtenção dos soros. Foi verificado que as propriedades físico-químicas do material recuperado estiveram próximas àquelas da terra nova, sendo obtidas diferenças percentuais de $6,1 \%$ para o $\mathrm{pH}, 12,8 \%$ para densidade aparente, $3,6 \%$ para o teor de umidade base seca e $1,4 \%$ em relação ao potencial de adsorção relativo. Desta forma, foi possível inferir que o tratamento térmico proposto não alterou consideravelmente a capacidade de adsorção da terra diatomácea, tornando-a reutilizável como agente filtrante no processo de produção dos soros.

Palavras-chave: Terra diatomácea, reutilização, soro antiofídico, soro antitóxico.

\begin{abstract}
In the production of antiophidic and antitoxic sera, it is common to use diatomaceous earth, which is a light mineral, with low specific mass and high adsorption potential, commonly employed in filtration processes. In order to reuse the residual earth from filtration processes of antiophidic and antitoxic sera of Fundação Ezequiel Dias, this work purposed its recuperation by thermal treatment. After Thermogravimetric Analysis of the residual diatomaceous earth, it was concluded that from $600^{\circ} \mathrm{C}$ all the impurities present in this material suffered degradation Thus, a sample of saturated mineral was heated in a muffle oven up to temperature of $700^{\circ} \mathrm{C}$. Then, the influence of the thermal treatment in the mineral properties was evaluated by means of the determination of the physicochemical parameters $\mathrm{pH}$, apparent density, dry basis moisture content and its adsorption potential in hiperimune horse plasma, the main characteristic for its application in the filtration process to obtain the sera. It was verified that the physicochemical properties of the recuperated material were very close to them of the new earth, being obtained percentage variations of $6.1 \%$ for $\mathrm{pH}, 12.8 \%$ for apparent density, $3.6 \%$ for basis moisture content and $1.4 \%$ in relation to relative adsorption percentage. Therefore, it was possible to infer that that the purposed thermal treatment did not vary its adsorption capabil-
\end{abstract}


ity considerably, making possible to reuse it as a filtration agent in the sera production process.

Keywords: Diatomaceous earth, reuse, antiophidic serum, antitoxic serum.

\section{INTRODUÇÃO}

Os acidentes por animais peçonhentos representam significativo problema de saúde pública em todo o mundo, mas, sobretudo, nos países tropicais, sendo o tratamento realizado pela administração de soros antiofídicos contra veneno de cobras e antitóxicos contra veneno de escorpiões e aracnídeos, principalmente [1]. No Brasil, os soros são produzidos pelo Instituto Butantan - São Paulo, Fundação Ezequiel Dias (FUNED) - Minas Gerais e Instituto Vital Brazil - Rio de Janeiro. Os lotes produzidos são comprados pelo Ministério da Saúde, que os distribui para as Secretarias de Estados de Saúde em todo país. O fornecimento para os acidentados é gratuito [2].

Os soros antiofídicos e antitóxicos são produzidos a partir dos próprios venenos, obtendo-se anticorpos específicos que são processados, diluídos e filtrados [3]. Durante o processo de produção e purificação dos soros antitóxicos, comumente utiliza-se terra diatomácea como material filtrante devido às suas atraentes características e propriedades físico-químicas para os procedimentos de filtração, como o fato de ser leve, porosa, quimicamente inerte e ser capaz de adsorver moléculas orgânicas [4,5]. Goulart et al.[6] definem a terra diatomácea como um sedimento amorfo, de natureza silicosa, que pode ser originado de organismos unicelulares vegetais. O material, que possui baixa massa específica, é composto essencialmente por sílica opalina, podendo-se encontrar também em sua composição elementos como alumínio, ferro, cálcio, magnésio, sódio e potássio, em menores quantidades.

Por apresentar elevada área superficial e baixa densidade, a terra diatomácea tem grande aplicação nos processos de filtração, principalmente na indústria de bebidas $[7,8]$, de purificação de água $[9,10]$ e biofarmacêutica [11,12]. Sua primeira aplicação com agente filtrante de plasma é reportado há mais de cinco décadas [13] e a filtração ocorre por meio de dois mecanismos principais: o primeiro é devido à formação de ligações de hidrogênio entre os grupos carboxila de proteínas aos grupos hidroxila do mineral e o segundo ocorre por adsorção física no interior de seus poros, que apresentam tamanho médio de 4 a $8 \mu \mathrm{m}$, levando a uma área superficial total de 3 a $100 \mathrm{~m}^{2} / \mathrm{g}$ [14].

Apesar da eficiência da terra diatomácea nos diversos campos de aplicação em que é empregada como agente filtrante, o resíduo gerado após a filtração pode ocasionar problemas de saúde, uma vez que a exposição frequente a este material pode levar ao desenvolvimento de problemas respiratórios, além de ser um passivo ambiental, já que seu volume como resíduo é cerca de três vezes maior em relação ao material antes da filtração [14]. Embora existam alguns procedimentos de regeneração do resíduo diatomáceo, geralmente o material é disposto em aterros sanitários ou são empregadas técnicas onerosas e que utilizam grandes quantidades de produtos químicos [15]. Desta forma, frente à crescente busca por práticas sustentáveis e implantação de processos mais baratos na cadeia produtiva industrial, este trabalho teve como objetivo o desenvolvimento de uma metodologia capaz de minimizar os custos e as perdas relacionados à produção de soros antiofídicos e antitóxicos através da recuperação, por via térmica, do resíduo de terra diatomácea para sua reutilização no processo de filtração dos soros.

\section{MATERIAIS E MÉTODOS}

Terra diatomácea utilizada no processo de filtração de soros antiofídicos e antitóxicos foi cedida pela Divisão de Produção de Imunobiológicos da Fundação Ezequiel Dias (FUNED, Belo Horizonte/MG). Amostras de terra diatomácea foram caracterizadas (em ensaios em triplicata) quanto aos parâmetros físico-químicos descritos nas seções subsequentes.

\subsection{Análise Termogravimétrica (TGA)}

Inicialmente o resíduo de terra diatomácea foi submetido a análise termogravimétrica a fim de se verificar em qual faixa de temperaturas ocorreria a degradação dos compostos remanescentes do processo de filtração do plasma equino, possibilitando sua reutilização na indústria. Para tanto, uma massa de 10,4 mg do resíduo foi colocada em um cadinho de alumínio sob fluxo de $83 \mathrm{~cm}^{3} \cdot \mathrm{min}^{-1}$ de gás $\mathrm{O}_{2}$ numa rampa de aquecimento de $10^{\circ} \mathrm{C} \mathrm{min}^{-1}$. O ensaio foi realizado num equipamento SDT 2960 Simultaneous DTA-TGA até a temperatura final de $900^{\circ} \mathrm{C}$ e, para a coleta e análise dos resultados, foram utilizados os softwares Thermal Advantage e Universal Analysis 2000.

\subsection{Tratamento térmico}


Uma vez determinada a temperatura de degradação dos compostos remanescentes do plasma presentes na terra diatomácea, amostra de terra diatomácea saturada com esses compostos foi submetida a tratamento térmico em um forno mufla LABOTEC com sensor de temperatura termopar tipo $\mathrm{K}$, sob temperatura de $700^{\circ} \mathrm{C}$ durante 6 horas. Após o tratamento, foram avaliados os parâmetros físico-químicos $\mathrm{pH}$, densidade aparente, teor de umidade base seca e percentual de adsorção relativo referentes às amostras de terra diatomácea nova, saturada e recuperada.

\subsection{Determinação do pH}

Para a aferição do $\mathrm{pH}$ das amostras de terra diatomácea nova, saturada e recuperada, inicialmente um volume de $100 \mathrm{~mL}$ de água destilada foi aquecida até $100^{\circ} \mathrm{C}$ e, em seguida, teve sua temperatura ajustada até $24^{\circ} \mathrm{C}$. Ao volume de água foram adicionados $4,0 \mathrm{~g}$ de amostra e essa suspensão foi homogeneizada durante 5 min por agitação magnética em consonância com o procedimento realizado por Goulart et al. [6]. Por fim, a solução foi filtrada a vácuo utilizando-se papel de filtro qualitativo num funil de Büchner e o pH do líquido filtrado foi aferido num pHmetro PHTEC.

\subsection{Determinação da densidade aparente}

O ensaio de determinação da densidade aparente foi realizado de acordo com o protocolo experimental descrito por Inglethorpe [16], pesando-se uma massa de $10 \pm 0,01 \mathrm{~g}$ das amostras de terra diatomácea e as submetendo a secagem em estufa a $105^{\circ} \mathrm{C}$. A cada intervalo de 5 minutos a massa das amostras foi aferida em balança analítica até que se obtivesse peso constante, o que indica a remoção total de umidade dos materiais. Em seguida, sem compacta-las, as amostras foram transferidas para provetas com capacidade volumétrica de $50 \mathrm{~mL}$, e o volume (v) ocupado pela massa $(\mathrm{m})$ de terra diatomácea foi relacionado à densidade aparente (d), por meio da equação 1 :

$$
d=\frac{m}{v}
$$

\subsection{Determinação do teor de umidade base seca}

Numa cápsula de porcelana previamente higienizada, foram colocados $10 \mathrm{~g}$ de amostra e o sistema foi submetido a aquecimento em estufa por $2 \mathrm{~h}$ a $106^{\circ} \mathrm{C}$. Ao final deste tempo, a amostra foi pesada e a diferença de massa observada pôde ser relacionada à evaporação de água do material, possibilitando a determinação de seu teor de umidade base seca.

\subsection{Determinação do potencial de adsorção}

Dada a função da terra diatomácea de filtrar componentes indesejáveis aos soros antiofídicos e antitóxicos em sua condição de trabalho na indústria, seu potencial de adsorção de componentes do plasma foi avaliado.

Plasma de equino hiperimune de concentração conhecida $\left(2,58 \mathrm{mg} \cdot \mathrm{mL}^{-1}\right)$ foi diluído, obtendo-se amostras com diluições de 0 a 100\% (intervalos de 5\%) para a obtenção de uma curva analítica de calibração de absorbância a $280 \mathrm{~nm}$ aferida num espectrofotômetro Pharmacia LKB-Ultrospec III.

Posteriormente à obtenção da curva analítica de absorbância a $280 \mathrm{~nm}$ em função da diluição do plasma, uma massa de $10 \mathrm{mg}$ das amostras de terra diatomácea nova, saturada e recuperada foram adicionadas a $2 \mathrm{~mL}$ do plasma equino sob agitação magnética de $200 \mathrm{rpm}$ a temperatura ambiente durante $1 \mathrm{~h}$ para promover a adsorção dos compostos orgânicos. Em seguida, as amostras foram centrifugadas a 5000 rpm por 30 minutos numa centrífuga HTMCT 2000 e os sobrenadantes foram coletados para se proceder com as leituras de absorbância.

Para o cálculo do potencial de adsorção das amostras, foi considerada a curva analítica obtida com as diluições do soro e os valores de absorbância das amostras de terra diatomácea.

\section{RESULTADOS}

A curva termogravimétrica gerada a partir do material diatomáceo saturado com os resíduos orgânicos dos soros antiofídicos e antitóxicos é ilustrada na Figura 1, onde se observa um primeiro estágio relativo à perda de massa em temperaturas de aproximadamente $100^{\circ} \mathrm{C}$, o que corresponde à evaporação da água fisicamente adsorvida no material. 


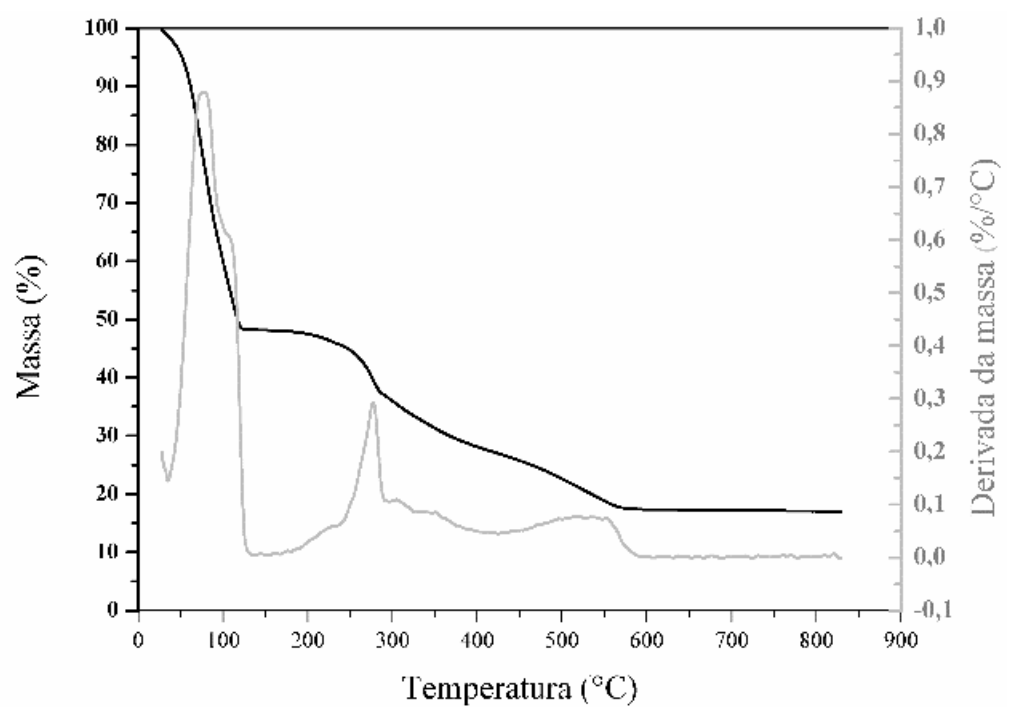

Figura 1: Curva de TGA para a amostra de terra diatomácea saturada

Em seguida, entre 100 e $300^{\circ} \mathrm{C}$ há uma segunda etapa de perda de massa provavelmente em consequência da eliminação de fenol (temperatura de ebulição de $187,1^{\circ} \mathrm{C}$ ) utilizado pela FUNED como agente conservante no plasma equino. Segundo Goulart et al. [6], nesta mesma faixa de temperatura pode ocorrer a eliminação de matéria orgânica de baixo peso molecular, e Souza et al. [17] apontam a perda de massa por desidratação da fase gibsita $\left(\mathrm{Al}(\mathrm{OH})_{3}\right)$ que é impureza presente na terra diatomácea, e pela perda de água de coordenação de cátions presentes em outros compostos do material.

Em até $600^{\circ} \mathrm{C}$ é provável a eliminação de matéria orgânica de maiores pesos moleculares, ao passo que para temperaturas superiores a esta verificou-se um estágio de massa praticamente constante, quando possivelmente os compostos orgânicos já haviam sido eliminados, restando apenas resíduo mineral não volátil proveniente da própria terra diatomácea. Considerando que a partir de aproximadamente $600^{\circ} \mathrm{C}$ não houve considerável variação de massa no material, definiu-se que para o tratamento térmico da terra saturada seria conveniente o emprego desta ou de temperaturas superiores para remover os resíduos presentes no material.

$\mathrm{O}$ efeito do tratamento térmico na amostra recuperada foi estudado comparando-se as propriedades físico-químicas deste material com as terras nova e a saturada de acordo com os resultados apresentados na Tabela 1.

Tabela 1: Parâmetros físico-químicos das amostras de terra diatomácea nova, saturada e recuperada por tratamento térmico

\begin{tabular}{l|l|l|l}
\hline $\begin{array}{l}\text { AMOSTRA DE TERRA DIA- } \\
\text { TOMÁCEA }\end{array}$ & PH & $\begin{array}{l}\text { DENSIDADE APARENTE } \\
\left(\mathbf{g} \cdot \mathbf{m L}^{-1}\right)\end{array}$ & $\begin{array}{l}\text { TEOR DE UMIDADE BA- } \\
\text { SE SECA (\%) }\end{array}$ \\
\hline Nova & $9,8 \pm 0,1$ & $0,187 \pm 0,011$ & $10,02 \pm 0,01$ \\
\hline Saturada & $4,6 \pm 0,3$ & $0,577 \pm 0,004$ & $4,27 \pm 0,03$ \\
\hline & $9,2 \pm 0,2$ & $0,211 \pm 0,007$ & $9,66 \pm 0,02$ \\
\hline
\end{tabular}

Os valores apresentados na Tabela 1 revelam maior similaridade de todas as propriedades entre as terras nova e recuperada, ao passo que a amostra saturada apresentou os menores $\mathrm{pH}$, teor de umidade base seca e capacidade de adsorção e a maior densidade aparente. 
A redução do valor de $\mathrm{pH}$ para a terra saturada pode ser explicado pela condição em que este mineral é exposto em sua condição de trabalho. Meer et al. [13] apontam que o abaixamento do $\mathrm{pH}$ em meios filtrantes pode diminuir a solubilidade de detritos celulares e impurezas portadoras de cargas negativas, como DNA e proteínas, facilitando o processo de filtração.

Quanto à densidade aparente, Tal fato se deve à grande quantidade de matéria orgânica presente neste material, ao passo que a pequena diferença de aproximadamente $13 \%$ entre os valores de densidade entre as terras nova e recuperada indicam boa eficiência do tratamento térmico que foi submetido esse material, liberando seus poros anteriormente preenchidos e proporcionando menor razão entre sua massa e volume. Inglethorpe [16] salienta que a terra diatomácea pura deve apresentar densidade aparente entre 0,2 e 0,4 g.mL $\mathrm{mL}^{-1}$, tal como foi verificado para as amostras nova e recuperada, enquanto maiores valores deste parâmetro são esperados quando o mineral apresenta impurezas. Além disso, a baixa densidade aparente do mineral diatomáceo é uma de suas características fundamentais para aplicação como agente filtrante, pois tem forte influência sobre seu empacotamento nos filtros de adsorção, sendo que materiais com altas densidades ocasionar alto grau de empacotamento de partículas, dificultando a passagem de adsorbato pela terra [18].

Em consonância com os resultados obtidos por Goulart et al. [6], que propuseram o tratamento térmico de terra diatomácea utilizada em processos de filtração na indústria cervejeira, as amostras nova e termicamente recuperada apresentaram grande similaridade de teor de umidade base seca (com diferença percentual de apenas 3,7\% entre si), reiterando a eficiência do tratamento térmico.

Para a determinação do potencial de adsorção relativo das amostras, foi considerada a curva de calibração expressa na Figura 2, a qual foi utilizada como referência e base de interpolação para determinação dos potenciais de adsorção das terras diatomáceas.

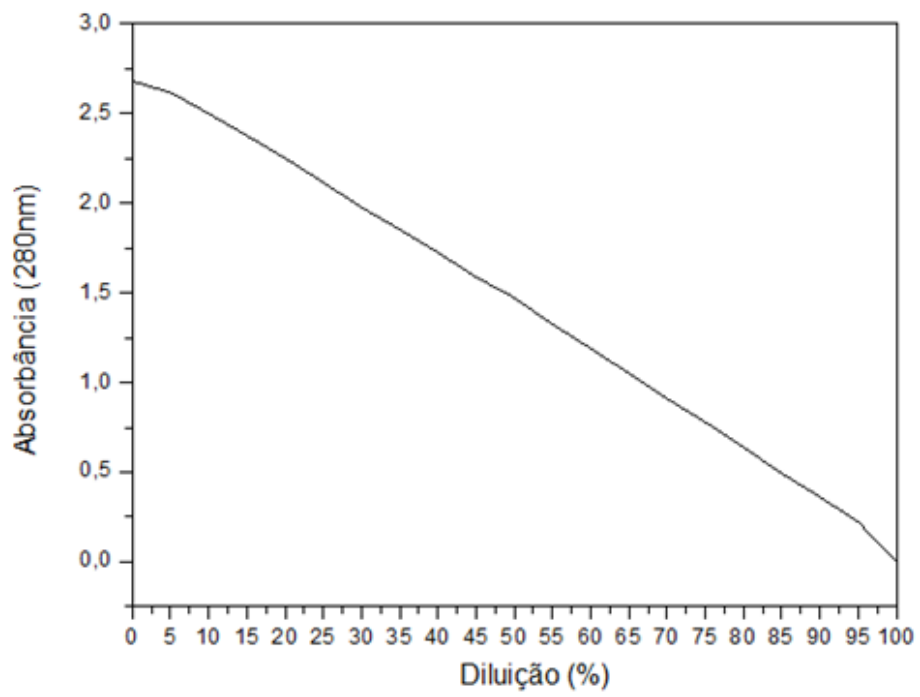

Figura 2: Curva de calibração para teste de potencial de adsorção relativo da terra diatomácea frente ao plasma equino

O gráfico revela a revela a relação diretamente proporcional entre a absorbância e a concentração das soluções, sendo obtidas maiores absorbâncias para as amostras menos diluídas. Assim, foram obtidos os respectivos valores médios de absorbância para as amostras de terra diatomácea nova, saturada e recuperada: 2,$221 ; 2,593$ e 2,230, o que corresponde aos potencias de adsorção expressos na figura 3 . 


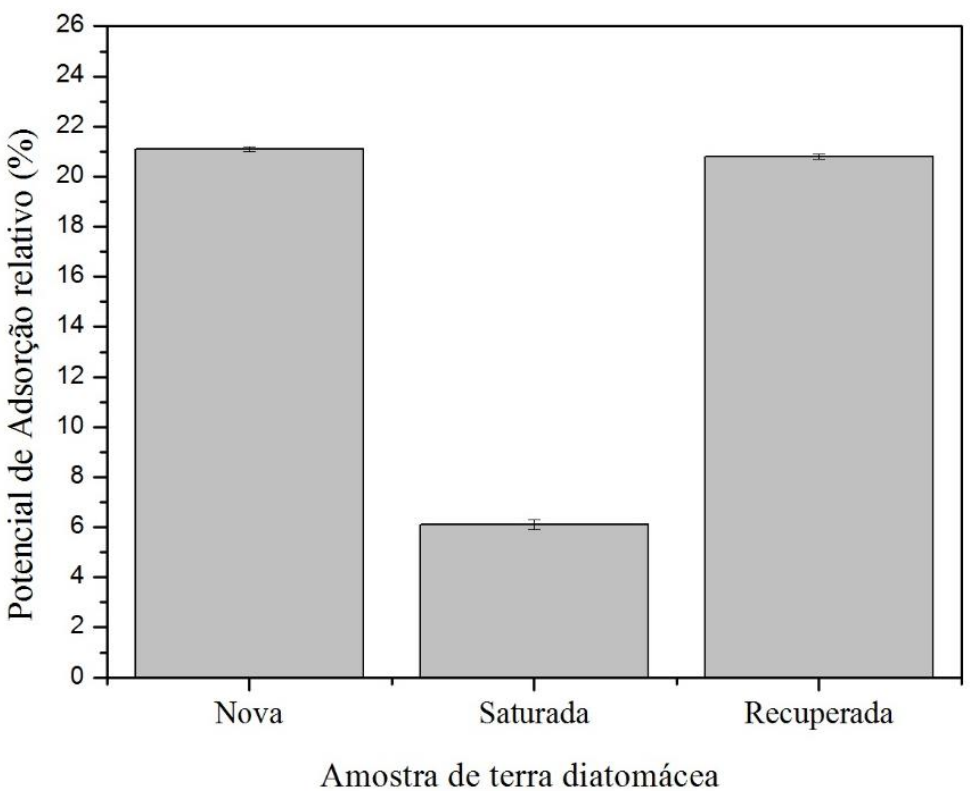

Figura 3: Curva de calibração para teste de potencial de adsorção relativo da terra diatomácea frente ao plasma equino

A análise do gráfico permite verificar que, como esperado, o potencial de adsorção relativo da terra diatomácea saturada é consideravelmente inferior ao da terra nova, uma vez que após o processo de filtração seus sítios de adsorção se encontram oclusos por impurezas provenientes do plasma equino, impossibilitando a efetividade de novas adsorções. No entanto, após o tratamento térmico, seu potencial de adsorção passa a ser igual a 20,8 $\pm 0,1 \%$, valor com diferença percentual de apenas $1,4 \%$ em relação à terra diatomácea nova. Ademais, os baixos valores de desvio padrão obtidos para este ensaio traduzem a reprodutibilidade do tratamento proposto.

\section{CONCLUSÕES}

Considerando a proximidade entre os valores dos parâmetros físico-químicos das amostras de terra diatomácea nova e recuperada, pode-se inferir que o tratamento térmico a que a matéria prima foi submetida não foi capaz de alterar significativamente suas características desejáveis para o processo de filtração para qual é destinada. Também o potencial de adsorção das impurezas do plasma equino confirmou a eficiência do processo de recuperação da terra saturada, ocasionando para a amostra recuperada uma capacidade de filtração bastante similar àquela da terra nova.

\section{AGRADECIMENTOS}

À Divisão de Produção de Imunobiológicos da Fundação Ezequiel Dias (FUNED) por cederem a terra diatomácea e os soros utilizados nesta pesquisa, bem como ao Laboratório de Química de Nanoestruturas do Centro de Desenvolvimento da Tecnologia Nuclear (CDTN), onde foram realizadas as análises termogravimétricas.

\section{BIBLIOGRAFIA}

[1] SISTEMA de Informação de Agravos de Notificação (SINAN), "Acidentes por animais peçonhentos", 2014. Disponível em: <http://portalsinan.saude.gov.br/acidente-por-animais-peconhentos>, Acessado em 2 mai 2016.

[2] INSTITUTO Butantan, “Como tratar picadas de animais peçonhentos”, 2014, Disponível em: <www.institutobutantan.com.br>, Acessado em 2 mai 2017.

[3] INSTITUTO Vital Brazil, Disponível em <www.ivb.rj.gov.br>, Acessado em 2 mai 2017.

[4] BHARDWAJ, V., MIRLISS, M. J., “Diatomaceous Earth filtration for drinking water. National Drinking Water Clearinghouse, Morgantown", 2001, Disponível em: < http://www.nesc.wvu.edu/pdf/dw/publications/ontap/2009_tb/diatomaceous_dwf>, Acessado em 18 jul. 2017. 
[5] MAFRA, G. P., "Desenvolvimento de Metodologia de microextração adsortiva em barra utilizando terra diatomácea para determinação de desreguladores endócrinos em água", Dissertação de MSc., Universidade Federal de Santa Catarina, 2016.

[6] GOULART, R.M., SILVEIRA, C. B., CAMPOS, M. L., et al., "Metodologias para reutilização do resíduo de terra diatomácea, proveniente da filtração e clarificação da cerveja”, Química Nova, v.34, n. 4, pp.625-629, 2011.

[7] GÓMEZ, J., GIL, M.L., DE LA ROSA-FOX, N., et al., "Formation of siliceous sediments in brandy after diatomite filtration", Food Chemistry, v.1, n. 170, pp. 84-89, 2015.

[8] BRAUN F., HILDEBRAND N., WILKINSON S., et al., "Large-scale study on beer filtration with combined filter aid additions to cellulose fibres", Journal of the Institute of Brewing, v.117, pp.314-328, 2011.

[9] GERBA, C.P., HOU, K., “Endotoxin removal by charge modified filters”, Appl Env Microbiol, v.50, n.6, pp. 1375-1377, 1985.

[10] GILGEN, M., GERMANN, D., LÜTHY, J., et al., "Three-step isolation method for sensitive detection of enterovirus, rotavirus, hepatitis A virus, and small round structured viruses in water samples", International Journal of Food Microbiological, v.37, pp.189-199, 1997.

[11] MINOW, B., EGNER, F., JONAS, F., et al., "High-cell-density clarification by single-use diatomaceous Earth filtration", Bioprocess International , v.12, n.4, 2014.

[12] CAMERON-SMITH, R., MILORADOVIC, L., CHEYNE, I., et al., "The removal of viruses during the purification of equine antisera using filtration aids HyfloSuper-Cel ${ }^{\mathrm{TM}}$ and Fulmont ${ }^{\mathrm{TM}}$ Super A", Biologicals, v.28, pp. 169-174, 2000.

[13] MEER, T., MINOW, B., LAGRANGE, B., et al., "Filtração com terra de diatomácea: conceito inovador na clarificação de cultura celular de alta densidade", Revista Contract Pharma Brasil, n.9, pp.24-29, 2015.

[14] POREDA, A., ZDANIEWICZ, M., STERCZYNSKA, M., et al., "Effects of wort clarifying by using Carrageenan on diatomaceous Earth dosage for beer filtration”, Czech J. Food Sci., v.33, n. 4, pp. 392 - 397 , 2015.

[15] TSAI, W.T., HSIEN, K. J., YANG, J.M., "Silica adsorbent prepared from spent diatomaceous earth and its application to removal of dye from aqueous solution", Journal of Colloid and Interface Science, v.275, pp.428-433, 2004.

[16] INGLETHORPE, S. D. J., Industrial Minerals Laboratory Manual: Diatomite, NERC science of the environment, p. 46, 2014.

[17] SOUZA, G. P., FILGUEIRA, M., ROSENTHAL, R., et al., Caracterização de material compósito diatomáceo natural, Cerâmica, v.49, pp. 40-43, 2003.

[18] BRAGA, R. M., "Uso de argilominerais e diatomita como adsorvente de fenóis em águas produzidas na indústria de petróleo", Dissertação de MSc., Universidade Federal do Rio Grande do Norte - UFRN, 2008. 